\title{
DE NÓS, DOS NÓS E DA IMPORTÂNCIA DO SIGNIFICANTE NO COTIDIANO DO VIVENTE
}

\author{
Mário Diógenes Poplade*
}

\begin{abstract}
RESUMO
O autor, fundamentando-se na Psicanálise como sustentação teórica para as articulações que realiza, discorre sobre a importância teórica do significante - tal como a Psicanálise o define - na vida cotidiana e geral do vivente. Para tanto, utiliza-se de alguns fragmentos de um caso clínico para demonstrar como "aparece" e é tomado o significante duma prática clínica, assim como para consubstanciar suas convicções sobre a importância da interpretação psicanalítica através do "corte" nas sessões de análise, finalizando por chamar a atenção para o lugar em que a Psicanálise situa o cerne de sua ação e sobre o valor da posição discursiva requerida e utilizada nas passagens singulares de cada um nesta "comicidade" denominada vida.
\end{abstract}

Psicanalista do Centro de Psicologia Aplicada (CPA) da Universidade Federal do Paraná; formado em Psicologia pela Faculdade de Filosofia, Ciências e Letras Tuiuti; formado em Pedagogia pela Universidade Federal do Paraná; mestre em Educação pela Universidade Federal do Paraná; coordenador de grupo de trabalhos e estudos sobre teoria psicanalítica. 
Palavras-chave: significante, falta, diferença, recalque, Psicanálise, análise, nó borromeano, N(ó)me-do-Pai, inconsciente.

\begin{abstract}
The author based in the Psychoanalysis like theoretical reference for joints, writes about the importance of the meaning - just as the definition of the Psychoanalysis - in the daily and general life of the alive. He also uses some fragments of a clinical case to demonstrate as "it appears" and how the meaning is taken into clinical practice. As well as to validate their convictions on the importance of psychoanalytical interpretation through the "cut" in analysis sittings. He conclude to call the attention for place that the Psychoanalysis situates the center of this action and on the value of the discursive position request and used in the popular passages of each in this "mockery" named life.
\end{abstract}

Desenvolvendo atividades regulares na Psicanálise, tive oportunidade de verificar a dificuldade das pessoas em entender e atribuir o devido valor ao trabalho deste principal fundamento da dimensão do registro do Simbólico denominado significante do cotidiano particular de cada um.

Constatei, dentro de suas mais particulares características, como estas pessoas manifestavam estas dificuldades - quer no percurso de suas análises, quer no interior de outras atividades, dos trabalhos, das discussões, etc. - quando sua atenção era chamada para a existência do significante na vida cotidiana e do vivente em geral. As dificuldades no entendimento se mostravam mais, evidentemente, com os participantes dos grupos de trabalho que me propus a coordenar.

Num primeiro momento, pensei que isto fosse devido ao posicionamento de não fornecer respostas prontas e acabadas às questões a mim dirigidas. Outra hipótese foi a de que além de não 
responder com detalhes as perguntas emitidas, sempre procurei fazer com que as próprias pessoas se implicassem nas dúvidas que apresentavam e passassem - de acordo com suas possibilidades - a responsabilizar-se pelo encontro das respostas mais plausíveis, tentando minimizar o incômodo provocado pelas questões que declaravam ter dificuldades em entender.

Alguns deram passos decididos nesta direção, mas devo confessar, não foi o caso da maioria. Isto teve efeito e supus poder contribuir com minha parcela, não somente continuando a coordenar os grupos de trabalho, mas também me pondo ao trabalho e me deixando tomar pelo significante. $\mathrm{E}$ assim procedendo, estudando o que havia antes registrado - restos escritos da minha própria experiência - tentei enunciar, uma vez mais, o que sempre restará para além de qualquer escrito.

Ponderei que seria produtivo retomar alguns de meus artigos anteriores, retrabalhar suas letras e, deixando-me trabalhar por elas, rearticulá-las. Propus-me a isto objetivando verificar o que ali se passava e até executar algo mais efetivo. Este algo mais efetivo, após este exercício de verificação culminou na conclusão de que o melhor procedimento seria continuar, um pouco mais, ainda, a registrar as rearticulações realizadas.

Com metodologia, adotei colocar-me o mais próximo possível da posição de aprendiz, coisa que, acredito, não deve ser difícil para alguém. Este procedimento se prende ao fato de que, se há algo de que tenho a mais absoluta certeza - e isto desde há alguns anos atrás, desde os primeiros contatos com a teoria psicanalítica, quando iniciei meu percurso na psicanálise - é que eu nunca mais deixaria de ser um estudante da teoria psicanalítica. E é por adotar esse tipo de convicção, como regra pessoal, que sempre procuro colocar-me diante das teorias de Freud e de Lacan como um analisante. Contudo, não como um analisante qualquer, mas como alguém em permanente formação. 
Está aí um bom termo para se iniciar algo, pois, ao se falar em formação, seja ela formação do inconsciente ou outra qualquer forma de ação, o significante sempre estará envolvido. Sendo assim, vamos à questão: o que é significante?

De pronto se pode adiantar que o significante tem como sua característica principal ser o símbolo de uma falta. Eis porque não se pode fazer o UM. Inclusive, é na busca de fazer UM que nós, os viventes, nos "acasalamos". Destarte, quando dois tentam fazer o UM, após aproximadamente nove meses (caso não se tome os "devidos cuidados"), aparece um terceiro e reinstaura a incompletude. Assim, na vigência de qualquer tentativa de totalização, de procura de completude, tem-se que inferir daí que há convívio com a falta, com a diferença, que há alteridade, ou seja, que ao vivente foi concebida a possibilidade de simbolização, a possibilidade de freqüentar o lugar da fala, isto é, o registro Simbólico, o registro da incompletude, porque também no campo do Outro - que pode ser entendido como uma cultura, uma língua, uma matriz de relações - falta um significante. Isto vem dizer que o Outro não é completo. Esta falta de um significante no campo do Outro, $[\mathbf{S}(\mathbf{A})]^{1}$ é o matema próprio da constituição do Recalque Primário. Daria para dizer que a falta de significante no campo do Outro $[\mathbf{S}(\mathbf{A})]$ é o Recalque Primário da Humanidade. É o que "forçou" o humano a ser desejante e, por conseguinte, falante.

Neste sentido, somos todos recalcados, o que eqüivale a dizer, bons neuróticos. Assim, é o significante que torna o humano capaz de um inconsciente e também propicia a este a capacidade de nomear, de simbolizar, enfim de definir as coisas através dos nomes.

E o significante é originário deste campo faltante, ou seja, do campo do Outro. Neste campo - antes que qualquer tipo de relação humana tivesse sido estabelecida - o significante já estava presente

Leia-se: $[S$ (A barrado) $]$ = Significante da falta de significante no campo do Outro. 
na natureza sob a forma de par opositivo. Ou seja, existia a claridade e a ausência dela. Depois, este fenômeno natural foi - por algo supostamente aparentado ao que viria a ser humano - arbitrariamente nomeado. Dizer nomeado é forçar um pouco as coisas, pois, se o contexto em que isto supostamente se tenha dado era prévio a qualquer pré-história, certamente o único som que aquela coisa viva de então poderia emitir seria algo como um ronco ou um grito. Um "kriahg" a la Tarzan das - agora já antigas - revistas em quadrinhos, ou um "grugh" ou qualquer coisa parecida com isto. $O$ fato é que tendo sido feita alguma designação para aquele fenômeno se pudesse atribuir um nome. Então deu-se para a presença de luz o nome de dia e para a sua ausência um outro nome aleatório, digamos, noite, e isto ficou estabelecido. Os demais componentes do grupo (bando ou horda) que daquilo ainda nada sabiam, quando necessitaram referir-se a este fenômeno tiveram que aderir à convenção estabelecida e passaram a utilizar então esses significantes. E isto veio sendo realizado num crescendo.

Essa digressão, que aos olhos de alguns poderia ser considerada banal, se faz necessária para acrescentar ainda que o significante contém pelo menos duas propriedades. Uma é a de estar ligado sincronicamente a outros elementos que lhe servem de substitutos. Exemplo disto é a metáfora tão comumente ouvida quando alguém se refere ao pai da moça como sendo "uma fera", querendo significar que ele é somente um pouco austero... A outra propriedade é a de estar disponível numa diacronia, encadeado metonimicamente, em que é seu o último termo que dará sentido à frase. Desta forma, uma pontuação decide o sentido da frase. Uma amostra disto já ocorria numa época pretérita, quando alguém profetizou: "Irás. Voltarás. Não morrerás ali”. O sujeito foi e morreu. Falha da profetiza? De jeito nenhum... Foi somente a concretização de uma evidência por não se ter levado em conta esta outra possibilidade de pontuação: "Irás. Voltarás? Não! Morrerás ali." 
Ao significante também se pode dar uma definição. A mais utilizada e, até certo ponto, transformada em "chavão" psicanalítico, é a que reza que o significante é o que representa um sujeito para outro significante. Observe-se que se trata de um sujeito que é representado para um outro significante e não de um vivente.

Disto então teremos que depreender que houve, na vida de um vivente, a entrada de um significante. Este significante "primeiro" ganhou o estatuto de ser um significante privilegiado é definido como sendo um S1. Este significante é aquele que inaugura uma série, depois deste $\mathbf{S} 1$ os demais, todos aqueles que o sucedem, são segundos. São outros. São S2.

O problema da compreensão sobre este S1 é que ele, mesmo sendo só um S1, não representa um só. O S1 é um enxame e no mínimo quando o vivente o recebe, vindo do campo do Outro, já o recebe como duplo, como dois. Ele é bifurcado, tal como a língua dos ofídios. É bífido.

Sendo bífido, o S1 porta já em si uma duplicidade. Ele traz em seu bojo aquilo que se poderia dizer que é positivo e ao mesmo tempo negativo. $O$ verso e o reverso. Mas note-se: só se pode dar estes nomes positivo, negativo, verso e reverso devido ao fato de o significante ter "adotado" o humano como seu vassalo, fazendo com que este - para poder fazer uso da fala, da linguagem - tivesse que alienar-se nele, não conseguindo mais viver sem ele. $E$ isto passou a constituir a existência do débito humano para com o significante. Sem ele não haveria possibilidade de qualquer tipo de escritura, de registro ou de simbolização.

É desta forma que na atualidade - e novamente fazendo uso de um exemplo banal - o que permite ao vivente dizer dia é o recalque do seu oposto, o seja, noite. Não se pode dizer noitedia, ou claroescuro, assim, de uma só e mesma vez. Ficaria incompreensível. É incompreensível. A divisão de noitedia e/ou de claroescuro é requerida 
por pura necessidade de transformação, para o estabelecimento de um referente. Ou seja, o referente de dia passa a ser noite e vice-versa. A separação, a existência dessa fenda sobre noitedia propiciou o advento de um diferencial - algo da ordem do estritamente particular, do absolutamente mais essencial e único para cada vivente -, o surgimento de um sujeito do inconsciente (\$). Inconsciente que é estruturado como uma linguagem. Assim, o \$ujeito do inconsciente é, para cada um, essencial e único. É essencial, diferencial e único porque esta noite e/ou este dia terão - para cada um e cada "entendimento" e contexto "na sua mais estreita particularidade individual" -, uma determinada significação. Até porque dentre os dias ou dentro das noites muita coisa pode acontecer...

Desta forma, há "outorgação" de um determinado significado devido à particularidade de cada "entendimento" e isto vem dizer da existência de um substrato, vem dizer da existência de um lugar Outro, de uma Outra Cena. É desta forma que inaugura-se a possibilidade do surgimento de um sujeito barrado (\$), pois ao ser aberta a fenda, como resultado, advém um espaço, um vazio entre noite e a respectiva significação, propiciando a sobra de um resto impossível de significarse completamente. Resto que é denominado objeto pequeno $\underline{\text { a. }}$.

Havendo esta fenda a este a, pode-se dizer que há (\$), assim como há Recalque Secundário. Assim, tem-se $[\mathbf{S}(\mathbf{A})]$ como a representação da castração no Outro, ou seja, que o Outro não é todo, não é inteiro, e o Outro (l'Autre) deve então ser barrado, [A], e (\$) como a representação da castração (entenda-se incompletude, falta, insatisfação) no vivente. A partir daí, há vigência do desejo (cuja causa é o objeto a ), da necessidade de substituição, da vontade, de inovação, de criação, da alegria, às vezes até de viver...

Em um outro artigo sobre a estruturação do \$ujeito (1914, p. 19), tive a oportunidade de discorrer um pouco mais sobre este (\$). Naquela ocasião, apontei que: 
É pela presença da falta de significante no código e da falta do sujeitoagente, que é aberta no interior da linguagem a refente (separação, fenda, divisão - termo utilizado por Lacan para designar a condição do sujeito que mascara a si mesmo ao fazer uso de enunciados forjados sobre si e sobre o que o cerca - do inconsciente. Esta é a condição que autoriza concluir que aí um inconsciente é possível ao vivente.

Neste sentido, pode-se dizer que a estruturação do sujeito coincide com a fundação do inconsciente. Inconsciente e sujeito se constituem num mesmo momento, no ato de falar, usar a palavra, utilizar o significante. Assim, é no significante mestre, S1, que o vivente particularizará e singularizará sua maneira de lidar com o real, ao ponto de Lacan denominar o primeiro significante da série, o $\mathrm{S} 1$, como sintoma do sujeito.

Então, tem-se um sintoma e para responder a ele são eleitos significantes. Contudo, o fato é que quando se elege um significante, se elege parte dele, para articulá-lo na linguagem. A "outra" parte, o seu contrário, age como referente e este referente necessariamente deve estar recalcado. Não fosse assim, não haveria qualquer possibilidade de dinamismo, de compreensão, de movimento na língua. Veja só... Movimento na língua! Observe-se quantas significações se pode dar a esta construção... É a duplicidade, a equivocidade do significante... O significante guarda, já em si, esta característica.

Mas atenção. Entenda-se: o oposto e/ou outras significações estarão recalcados para aquele preciso momento. Em outro contexto, seria o reverso que apareceria quando o verso estivesse recalcado e assim por diante... Assim, quando se diz recalcado, não é xingamento. Recalcado quer dizer não excluído para todo sempre, mas sim "apagado" momentaneamente e por isto com possibilidades de retorno. O que está recalcado não está foracluído. O recalcado tem possibilidades de retorno e isto ocorre com mais freqüência no nosso cotidiano que a vã filosofia possa imaginar. Mas há um porém: geralmente o que está recalcado o está porque em algum contexto, em algum sentido, em alguma combinação de letras ele porta algum desprazer e/ou se for pronunciado, denunciará um desejo que alguma 
instância não quer e/ou não pode admitir e é por este motivo que ele é mantido como "esquecido". Assim, enquanto o contexto permitir as palavras podem afluir sem qualquer problema; em outros, nem tanto, chegando a obrigar seu emitente a justificar-se com o já célebre: "não era bem isto o que eu queria dizer..."

Em outras ocasiões, e isto parece ser do conhecimento geral, pode-se constatar a reação de pessoas que diante de um determinado contexto ficaram mudas, sem palavras, impossibilitadas de descrever a cena que presenciaram. Diante dessa "impotência" tentam "montar" uma teoria para justificar o porquê do mal-estar, da indignação ou do "travamento". Isto acontece até com as mais proeminentes personagens das melhores famílias, desde que sejam falantes, naturalmente...

Para melhor ilustrar o que está sendo tratado aqui, vamos nos valer de alguns fragmentos de um caso clínico.

Uma determinada pessoa veio até meu consultório com a queixa de que não sabia mais conviver com as pessoas; que se sentia envergonhado em se dirigir às pessoas; se sentia impossibilitado de estabelecer amizades e contatos sociais. Em suma, esta pessoa estava com dificuldades em encontrar uma maneira de interagir com o social, vale dizer, com o Outro Social. Naquela ocasião assim se referia: "Sinto-me como se estivesse submergido num mar de nada. Nada me interessa. De nada eu gosto. Não há nada que me motive. Não vejo nada de bom ao meu redor." Nada o interessava, de nada ele gostava: "Me transformei num misantropo."

Nas entrevistas preliminares relatou que ao completar dezesseis anos foi enviado para o Paraná para continuar seus estudos, passando a freqüentar um curso preparatório para fazer Teologia, uma vez que desejava muito tornar-se padre. Assim, ele era aluno de um internato, pertencente a uma determinada ordem.

Devido ao tempo no internato e sua grande cultura, gozava de certas prerrogativas e responsabilidades dentro daquela ordem, a ponto, a ponto de ser encarregado de proferir palestras, coordenar retiros etc. 
Numa ocasião foi realizada uma espécie de avaliação com entrevistas etc. Era uma avaliação de passagem para um grau mais elevado na direção de ser ordenado padre. Alguns dia depois desta avaliação ter sido feita, comunicaram-lhe que ele não detinha as qualificações necessárias. Alegaram que ele havia incorrido em algumas faltas e que estas faltas o desabonavam para a ordenação que pretendia. Assim: "Fui convidado a me retirar da ordem."

Convidado a se retirar do internato, passa a andar sem rumo pela cidade. "Eu passei 15 anos lá dentro e agora, com isso, deixei de ter referências... Depois que fui mandado embora, me senti como solto no ar."

Todos os seus familiares residiam na região Nordeste do Brasil e o fato de estar estudando para ser padre era motivo de orgulho tanto para ele quanto para sua família. Ele não havia contado aos familiares o que tinha acontecido e também não tinha qualquer intenção em voltar para casa, pois: "Eles iriam ficar muito tristes. Isso seria uma grande decepção para eles. "Não tinha residência fixa, estava sem emprego e sem dinheiro (havia feito voto de pobreza, etc.).

Depois de algum tempo perambulando sem rumo pela cidade (mais ou menos uma semana), encontrou umas pessoas que haviam participado das atividades religiosas que havia coordenado, ministrado ou coisa assim. Elas o reconheceram e: "Foi com muito custo que contei-Ihes o que havia acontecido comigo." A partir daí, passou a morar na casa de uma dessas pessoas, que no início o ajudou e o subsidiou, inclusive, financeiramente. Logo em seguida conseguiu emprego, mas optou por permanecer na residência das pessoas que o acolheram.

Em análise, reputando-se como respeitador das mulheres - "às quais tenho em alta consideração" - questionando-se sobre a reconstrução de suas relações sociais, se teria capacidade de relacionar-se afetivamente com alguma moça, sobre se era ou não inteligente, sobre como 
poderia fazer para acrescentar mais conhecimentos aos que já possuía e definindo-se como "um amante do saber pois sempre fui e me considero um cara aberto à cultura, à instrução", emite essa pérola de construção que geralmente só é proferida na ausência de qualquer saber sobre o que verdadeiramente se está falando. "Se agora eu me aproximar de alguma mulher é só para aprender algo a mais... A bem da verdade, das mulheres só quero algo que me instrua."

Nada de conveniente quanto a se instruir. Afinal, para um exseminarista, detentor de uma imensa cultura - alguém que foi alijado de ser ordenado padre, o que frustrou a aspiração pessoal e familiar de torna-se um partícipe de uma "monástica e espiritual vida" - soava lógica sua intenção de aumentar seu já enorme saber. Contudo, mesmo no interior deste seu imenso "saber", ainda havia lugar para algumas "faltas" de conhecimento. Desconhecia que esta "energia" em direção ao saber - tinha um ponto de origem. E o significante, na sua "imperatividade", veio a denunciar de uma só vez tanto esse ponto de origem (a existência de um desejo inconsciente), quando sua curiosidade sexual infantil (que até então duvidava que existisse no ser humano), através deste enigmático "algo que me instrua". - Menstrua?

A pontuação efetuada o deixou indignado; argumentou que não era nada disso que ele queria dizer etc. No dia seguinte telefonou para comunicar que estava cogitando a possibilidade de não mais retornar à análise, apresentando como justificativa problemas com os horários e coisas do gênero. Dois dias depois, liga para confirmar o horário da semana seguinte.

Algumas semanas mais tarde, inicia sua sessão fazendo alusão à época em que foi convidado a se retirar da ordem e relata: Saí de lá somente com meu hábito: nada mais."

Ao ser interrompida a sessão de análise sobre essa construção Ihe foi oportunizada a possibilidade de trabalhar com o equívoco significante contido nesse "Saí de lá com meu hábito". 
Uma vez chamada sua atenção para o equívoco, passou a associar e a discorrer sobre o hábito de um personagem bíblico chamado Onã. A partir de então - ainda que com muitas dificuldades - "um outro seu lado" até então por mim insuspeitado, autorizou-o a "vir conversar na sessão". Passou a relatar seus hábitos onanistas. Passou a relatar que se masturbava compulsivamente, e que para se excitar construía encenações homossexuais. Na seqüência, viria a acrescentar ainda que as faltas que o desabonavam e que culminaram o "convite" para retira-se da ordem eram devidas ao fato de ter sido denunciado por masturbação e envolvimento homossexual com outro aluno dentro do internato.

Depois, relatou o realmente ocorrido. Relatou que havia sido expulso da ordem. "Na verdade fui expulso. Fui excomungado como um Judas e obrigado a sair de lá só e com meu hábito." Na seqüência, acrescentou também acreditar que além deste "seu hábito" bem poderia ser verdade que "das mulheres só queria algo que menstrua". Quem sabe esse desejo inconsciente e por isto mesmo desconhecido fosse um dos coadjuvantes nas suas dificuldades em estabelecer amizades e contatos sociais.

O fragmento acima exposto poderia ser tomado como uma das várias possibilidades da manifestação da "imperatividade" do significante no cotidiano do vivente. Além disso, há toda uma outra consideração que se pode fazer sobre o valor do significante para o ser humano.

Diz Lacan: "O significante é de saída imperativo" (O Seminário Livro XX, 1972-73 p. 45). Imperativo vem dizer de algo que aponta com rispidez, que denuncia, que delata, ordena. A imperatividade do significante pode ser sentida até pelo fato de que não somos nós que o utilizamos. Somos utilizados por ele. Somos empregados da linguagem e escravos do significante. Não somos nós que utilizamos a linguagem, é ela que nos utiliza através do significante. $O$ significante, então, se impõe. Age tal como se tivesse vida própria. Isto se pode constatar até em algumas doenças ditas psicossomáticas. Algo ali "fala" mesmo 
sem ter boca. Nesse sentido, para o humano "bye-bye" qualquer suposta liberdade... em contrapartida, é o significante que nos dá possibilidade de posicionarmo-nos, de assumir-mos uma posição discursiva. E posição discursiva vem dizer de uma postura ética diante de nossos ditos.

Isto não quer dizer que, ter estudado, ou saber exercer com mestria o "poder" da oratória, ou "falar bem" ou ainda ter "passado" por uma análise, acabou, que não há problema... "Curou-se". Muito pelo contrário,como diz Freud em algum lugar da sua obra: "quanto mais intelectualizado, mais neurótico é o homem". O humano não tem cura. Não tem cura pelo "simples" fato de que, sendo refém do significante e necessitando dar consistência à palavra, é obrigado a engatar seu dizer no discurso se for sua pretensão credenciar-se a algum acesso à verdade e à ética. Ética da psicanálise, que não se fundamenta na ordenação dos bens ou no caminho da felicidade.

O vivente maduro, sob o ponto de vista da psicanálise, é aquele capaz de fazer a escolha dos bens a partir da exclusão dos falsos bens, por saber detectar o seu desejo. É desta forma que a sublimação se inclui na dinâmica metonímica do desejo, ao promover a mudança de alvo em que o preço pago é o gozo.

A psicanálise, situando no cerne de sua ação o desejo inconsciente, não promete a panacéia para quem se arrisca nesse domínio. É devido a isto que a travessia analítica comporta uma espécie de risco na confrontação com o desejo. Avançar numa análise dando-lhe continuidade (nem diria levá-la até seu término) implica uma decisão. Eis porque se torna necessário que o analisante fale, enuncie se é isso o que ele quer. Pois toda ação é habitada pelo desejo. Contudo, é próprio da experiência analítica efetuar o questionamento do sentido desse desejo. A ética da psicanálise comporta o tempo de interrogar esta experiência trágica, em que a questão do desejo é sustentada até as últimas conseqüências. 
Este posicionamento vai ao encontro do que LACAN, em $O$ momento de concluir (Seminário XXV; 1977-78), estabelece, ou seja:

O psicanalista é um "retórico" que "retorifica" e "retifica". "As palavras fazem as coisas", mas justamente a psicanálise "se ocupa da inadequação das palavras das coisas". (...) "a vida não é trágica". Ela é "cômica". Freud errou ao escolher o complexo de Édipo, uma tragédia, para designar "isto com que tinha que lidar na relação que liga o Simbólico, o imaginário e o Real”.

Desta forma, o ganho que uma análise pode propiciar é o advento no vivente do pouco de realidade que sustenta seu desejo mais além do imaginário. Pois o único bem reconhecido pela Psicanálise é aquele que serve para pagar o preço para o acesso ao desejo inconsciente, que é a própria metonímia do nosso ser.

Parafraseando Lacan, a posição ética do sujeito se refere ao pagamento da dívida pelo desejo satisfeito. Seu meio é o acordo da palavra através da experiência subjetiva, na qual é possibilitado o reconhecimento do desejo inconsciente que se articula no dizer.

É devido a isto que, uma vez dentro da situação analítica e do contexto transferencial, este dispositivo psicanalítico denominado corte da sessão pode e deve ser utilizado. Sua utilização pode ser realizada de duas formas: ou na diacronia metonímica do discurso, quando da ocorrência de formações do inconsciente (que se constituem como as mais fidedignas expressões, ainda que na forma de "ruínas" do desejo inconsciente), ou na sincronia metafórica, na forma mais direta e pontual de denúncia do desejo inconsciente. Destarte, isto só pode ser levado a cabo e surtir efeito devido ao fato de que é a linguagem que nos constitui como humanos e que estrutura o inconsciente. Assim, é na palavra e pela palavra que o vivente é constituído. Portanto, aqueles que privilegiam trabalhar com uma Outra escuta, como é o caso do psicanalista, orientam seu interesse para a falha, para o tropeço da palavra no discurso. 
Desta forma, em Psicanálise, a utilização dos dispositivos analíticos - dentre os quais se inclui o corte da sessão - efetiva-se sobre todas as formações do inconsciente e estas nada mais são que aqueles atos em que estejam envolvidas palavras, chistes, sonhos, esquecimentos, atos falhos, lapsos... ou seja, em toda e qualquer manifestação do significante. Significante que se constitui em uma ordem de espaçamento dentro do qual o que se inscreve é a Lei enquanto presença da pura diferença.

Desta maneira, e por privilegiar a escuta das formações do inconsciente - inconsciente onde não existe qualquer registro do que seja tempo cronológico - é que o analista pode promover cortes na sessão. Cortes que não devem ser tornados no sentido de que as sessões sejam curtas ou longas, mas com uma referência, pois o corte da sessão, para Lacan (assim como para os analistas que privilegiam adotar este dispositivo analítico), tem efeitos de interpretação e precipita momentos conclusivos.

A interrupção que se faz em uma sessão é da ordem de uma decisão do analista. Esta decisão é estabelecida através do que se denomina ato analítico. Ato analítico na forma de corte. Corte que é, sem dúvida, o modo mais eficaz de intervenção e de interpretação analítica.

Sendo assim, o analista pode e deve "cortar no significante", obrigando o analisante a reconsiderar seu quadro geral. Contudo, quase que imediatamente sempre advém a "retomada do controle das coisas", e o vivente, remendando a falha e preenchendo com sentido aquilo que não foi consentido, convalida e justifica a presença do recalque. Recalque do quê? De significantes.

Eis aí o valor do significante na vida cotidiana de cada um. Por aí se poderia falar, inclusive, de destino. Destino que não há, pois quem governa o discurso do vivente é o significante.

O "entendimento" da Psicanálise é o de que todo vivente é inteiramente determinado pelo deslocamento do significante. E o 
nosso pretenso destino se organiza em torno de certos significantes e estes determinam nossos atos. Inclusive os de palavra.

Os significantes determinam os viventes tanto em seus atos, em seu destino, em suas recusas, quanto em seus enceguecimentos, em seus sucessos, em sua sorte. Eis o porquê da prática analítica ser a decomposição do significante até sua mínima expressão à letra. Procede desta forma para que se soltem todas as amarras de fixação possíveis de serem soltas e para propiciar que o vivente possa recompor o seu sintoma em uma outra cadeia significante. Significante este que - tendo-se em conta o Nó Borromeano - resta assentado como borda entre o Real e o Simbólico. Ou seja, o lugar da subjetividade. Subjetividade que se "expressa" através de posições discursivas, posições éticas, atos de palavra, de significantes.

Nesse sentido é muito rico e importante verificar como o autor do livro Os Impasses do amor (SOUZA, A.M.) toma Platão, Sófocles e Guimarães Rosa para nos ensinar sobre as respectivas posições éticas de Sócrates, Antígona, Riobaldo e Zé Bebelo perante seus ditos.

A partir daquele livro, e com grande satisfação, pude depreender e aprender um pouco mais sobre o valor da história de um vivente. Sobre o valor das passagens singulares de cada um e de como durante essas passagens a posição discursiva é requerida e utilizada. Da importância de nosso posicionamento diante das coisas cotidianas da vida. Da nossa história. Do pouco valor que damos aos eventos que nos cercam, assim como aos nossos semelhantes. Do quanto desrespeitamos nossos semelhantes somente por portarem uma marca diferencial que é o que os caracteriza como tal. Da pouca importância dada aos acontecimentos que, apesar da nossa negligência para com eles, não são impedidos de fazer marcas em nossa subjetividade e a partir daí causar efeitos, transformar uma vida.

$\mathrm{E}$ isto tudo por quê? Por que o significante está aí.

No entanto, há significante e significante. 
Retomando o que até então vinha sendo desenvolvido no início, pode-se afirmar que há um significante que é "primeiro" e é privilegiado. Sem ele não tem "conversa" (nos dois sentidos da palavra), não tem travessia nem travessura.

Está se falando daquele famoso ÉSSE 1 (S1). Mas aí têm-se mais alguns detalhes. Esse ÉSSE 1 (S1) também é denominado de Nomes-do-Pai.

Bem... antes era a família, depois algo que me instrua e depois masturbação e "cortes" na sessão. E agora vamos mexer com o pai, com o (Nó)mes-do-Pai?

Pois é: teremos.

Teremos que mexer com este nó. Teremos que mexer com o pai e com a morte, porque, conforme LACAN - em seu seminário Las formaciones del inconsciente (Seminário V; 1957-58, Lição de 26/03/58) - é o assassinato do pai que esconde "o elo estreito que existe entre a morte e o aparecimento do significante". Leiam o Totem e tabu (1913) de Freud. Desta forma, a morte está presente no aparecimento do significante. Um assassinato se fez presente na nossa pré-história e a propiciou a constituição dos Nomes.

É sobre estas bases que se assenta um (nosso pecado original?) sentimento - dito por Freud, inconsciente - de culpa do, e a possibilidade de, ser humano.

Como se vê, "a coisa" não é tão simplória como pode aparentar. Em nós, existem "amarrações" e "Nós". E por isto requerentes de melhor explanação. Por exemplo: em Psicanálise trabalha-se com o que são denominadas instâncias psíquicas. E o suporte destas instâncias psíquicas é denominado Nó Borromeano. 
Este Nó é a estrutura mínima e tópica do falante. E além de ser composta pelos registros real, simbólico e imaginário, faz parte daquilo que em Psicanálise denominamos Topologia. Capítulo especialíssimo da Epistemologia (Ciência do Comportamento), cuja geometria qualitativa é sem mediação, onde não se trata de distâncias, de dimensões e/ou volumes e onde não se tem outra coisa senão a rede sistemática do significante para suportar os objetos. Assim, a Topologia é a estrutura. Estrutura tal qual a Psicanálise a entende e Lacan (O Seminário, Livro III, 1955-56, p. 209-210) a estabelece, ou seja:

A noção de estrutura merece por si mesma que nos detenhamos nela. Tal como a fazemos funcionar eficazmente na análise, ela implica um certo número de coordenadas, e a própria noção de coordenada dela faz parte. A estrutura é em primeiro lugar um grupo de elementos formando um conjunto covariante.

Eu disse um conjunto e não uma totalidade. Com efeito a noção de estrutura é analítica. A estrutura se estabelece sempre pela referência de algo que é coerente com algo diverso, que lhe é complementar. 
Eis aí pelo menos um dos motivos para a presença desse Nó e da sua importância em nós. Desta forma e para aqueles que tiverem curiosidade e/ou interesse em conhecer um pouco mais sobre essa figura topológica ou sobre as possibilidades de trabalho que ela nos abre, poderão reportar-se a um outro artigo meu, publicado na revista Psicologia Argumento - Ano XIII, n. XVI, abril de 1995, p. 75-93, intitulado: "Sobre o sintoma: algumas considerações sob o enfoque psicanalítico."

Por ora, poderia adiantar-lhes que este nó só funciona entrelaçado nele mesmo de forma que lhe é muito particular. Ademais, e tal como tive a oportunidade de desenvolver no artigo acima referido, "Amarrado os três registros deste Nó (que deve ser intuído na sua tridimensionalidade), há este quarto elemento, esse $\mathbf{S 1}$, denominado Nomes-do-Pai, cuja presença faculta ao humano a frequentação no discurso. Faculta ao humano ocupar um lugar da fala. No código. Na linguagem." (Poplade, 1995, p. 86)

Nomes-do-Pai

É desta forma que o psiquismo humano, na visão psicanalítica, comporta o Nó Borromeano "amarrado" pelo Nomes-do-Pai que anola os registros: real, simbólico e imaginário. $E$, a partir da entrada do InterAÇÃO, Curitiba, v. 2, p. 29-50, jan./dez. 1998 
Nomes-do-Pai, da tomada do ser pelo significante - e apesar de constante e reiteradamente não se querer saber de nada disso -, é com o desejo inconsciente que cada um de nós teremos que nos haver. $\mathrm{E}$ isto se faz não sem alguma resistência. Dentre as várias, uma dentre as possíveis resistências com as quais muitos nos defrontamos ainda é a presença dessa instância que não sabe calcular, julgar ou pensar, o que não a impede de trabalhar. Este trabalhador ideal se chama inconsciente.

Ao retirar a certeza egóica de que o ser humano seria o senhor absoluto dos seus atos, Freud provocou um profundo descentramento do narcisismo humano. E a partir do momento em que foi proposta e foi provada a existência de uma instância outra que se interferia e interfere diretamente sobre nossas vidas de maneiras as mais variadas possíveis, Freud mexeu, inovou, descentrou a cultura de sua e da nossa época.

Através da história do movimento psicanalítico, nos foi possível saber que sempre houve resistências e não entendimentos do que seria este conceito fundamental da Psicanálise, denominado por Freud de Inconsciente.

Atualmente, aceita-se a idéia do que é Inconsciente, reconhece-se o conceito de Inconsciente e suas formações, mas é necessário, ainda, aceitar que o Inconsciente não é o lugar das divindades da noite, não é um inimigo, nem quadrado nem redondo e tampouco pode ter uma representação a nível linear. Isto quer dizer que esta geometria que conhecemos e dominamos, a geometria euclidiana, não corresponde em absoluto àquilo que é o "processo inconsciente". Processo cujo conceito fundamental, segundo Lacan, o único mito moderno: o mito do parricídio.

Concorda-se com o "conceito de inconsciente" e maneja-se este conceito. Trabalha-se com ele seriamente e acredita-se na sua estruturação como uma linguagem. Entretanto, quando se trata de figurá-lo e ter uma intuição deste "inconsciente", fica-se muito aquém de onde se chegou do ponto de vista conceptual. 
Mas existe a possibilidade de que através da análise, do trabalho, nós, com os nós, com a Topologia, possamos abrir novos caminhos para uma aposta de descentramento, de sideração, de deixar-se de trabalhar pelo significante e provocar um afastamento das posturas assemelhadas às dos reducionistas, que, no dizer do professor A. BOURGUIGNON (1981, p. 121)

É reducionista todo discurso que pretenda dar conta da realidade considerando-a unicamente por seu próprio ponto de vista. Todo discurso sobre o ser humano não pode ser outra coisa senão uma polifonia. Disso sabia Freud, que entrecruzava toda sorte de considerações onto e filogenéticas, psicológicas, sociológicas, etc. E vê-se que essa é uma das causas da longevidade da sua teoria do aparelho psíquico, que nisso se distingue e se afasta das considerações relativas ao tratamento psicanalítico, onde tudo se reduz ao aqui e agora. 


\section{REFERÊNCIAS BIBLIOGRÁFICAS}

BOURDGUIGNON, A. O conceito de renegação em Freud. Rio de Janeiro: Jorge Zahar Editor, 1991.

LACAN, J. M. As psicoses. O Seminário. Livro III, 1955-56. Rio de Janeiro. Jorge Zahar Editor, 1978.

Las formaciones del inconsciente. Livro V, 1957-58. Xerox.

Mais ainda. O Seminário, Livro XX, 1972-73. Rio de Janeiro: Zahar Editores, 1975.

O momento de concluir. Livro XXV, 1977-78. Xerox.

POPLADE, M. D. A estruturação do sujeito. Revista de Ciências Humanas, Curitiba, n. 15, p. 19, set. 1994.

Sobre o sintoma: algumas considerações sob o enfoque psicanalítico.

Revista Psicologia Argumento, Curitiba, n. 16, p. 28, abr. 1995.

SOUZA, A. M. Os impasses do amor. Porto Alegre: Artes Médicas, 1996. 